\title{
High-throughput sequencing in vaccine research
}

\author{
Katarzyna Pasik $^{1 凶}$, Katarzyna Domańska-Blicharz ${ }^{2}$ \\ ${ }^{1}$ Department of Veterinary Pharmacy, ${ }^{2}$ Department of Poultry Diseases, \\ National Veterinary Research Institute, 24-100 Puławy, Poland \\ katarzyna.pasik@piwet.pulawy.pl
}

Received: October 20, 2020,

Accepted: May 11, 2021

\begin{abstract}
The world of vaccines has changed tremendously since the time of Louis Pasteur. In the present day, it is regarded as vaccinology, a discipline which includes not only the knowledge of vaccine production, strategies for its delivery and influence on the clinical course of disease and the response of the host immune system but also regulatory, ethical, economic and ecological aspects of their use. A hundred years after Pasteur created the first vaccine, there was another scientific breakthrough of great importance in this field, i.e. Sanger sequencing. Progress in genome sequencing and other molecular techniques over the intervening 40 years has been enormous. High-throughput sequencing (HTS) platforms and bioinformatics tools are becoming widely available, falling in cost, and results are achieved very quickly. They enable the construction of modern vaccines, as well as the assessment of their safety, effectiveness and impact on the host organism and the environment. These techniques can also provide a tool for quality control of vaccines. Unprecedented possibilities are opened up by the HTS technique, but limiting factors on its implementation have to be contended with such as lack of reference materials and problems with method optimisation or validation. In the face of the current COVID-19 pandemic, a significant role is allotted to this sequencing technique while an effective vaccine against the disease caused by SARS-CoV-2 is sough.
\end{abstract}

Keywords: HTS, NGS, vaccine.

\section{Introduction}

The progress made in research and dissemination of vaccines since Pasteur's time is astounding today. In the 1880 s, it was not suspected that the vaccine would trigger such a revolution in medicine and pharmacy. The first Pasteur biopreparations were four vaccines: against cholera, anthrax, swine erysipelas and rabies. These vaccines were simple products with a short shelf life, containing weakened or killed pathogens preserved in alcohol. They were produced initially in small laboratories in quantities depending on the demand. In the following years, the production of vaccines moved to large laboratories of pharmaceutical companies, which allowed a large proliferation of antigens in a variety of vaccines produced and massive rise in the number of doses in human and veterinary medicine. Currently, there are over 100 times more veterinary vaccines on the market in Poland than in the time of Louis Pasteur. Only a hundred years after Pasteur created the first vaccine, there was another scientific breakthrough of great importance in this field, i.e. the
Sanger chain termination method of sequencing. These two unconnected research directions meet today as long years of research culminate in major progress, and their combination gives new opportunities. What is occurring in vaccinology may now be acclaimed as evolution if the impetus of new vaccine creation and the inclusion of new pathogens in vaccine composition are recognised appropriately (Fig. 1). The development of new vaccines has been driven by the modernisation of molecular biology techniques. The turning point was the introduction of high-throughput sequencing for immunological study of medicinal products.

At the end of the 20th century, the first instruments for automated DNA sequencing by capillary electrophoresis were introduced, the so-called "first generation". The technique was the Sanger method, which allows the reading of DNA sequences. It involves the process of copying the DNA molecule in vitro catalysed by DNA polymerase (40). Thanks to automation, the Sanger method has become widely used $(4,9)$. This technique enabled sequencing of the entire genome of the $\Phi \times 174$ phage of $5,400 \mathrm{~kb}$, the human 
mitochondrial genome $(16.6 \mathrm{~kb})$ and that of phage $\lambda$ $(48.5 \mathrm{~kb})$ in a short time from its first introduction. This achievement is considered to be a breakthrough in the science of sequencing (32).

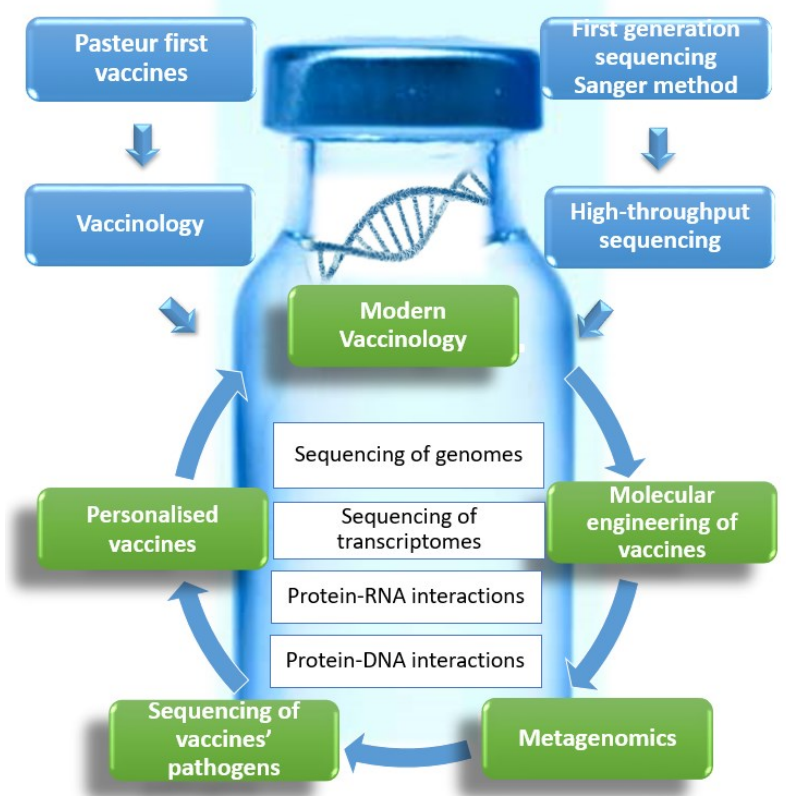

Fig. 1. Parallel development of HTS technology and vaccinology

In 2005, it was time for the "next generation" instruments giving the possibility of sequencing from $84 \mathrm{~kb}$ per run to 1 gigabase $(\mathrm{Gb})$ per run, a short read, mass technique and parallel sequencing - high-throughput sequencing (HTS) previously more commonly referred to as next-generation sequencing (NGS). It is used in various fields of science. HTS yields much larger datasets at a much lower cost than the Sanger method. The current progressive platforms give highly parallel sequencing, with a result of a higher order of magnitude (5) (Fig. 2). The development of genome sequencing technology has high momentum. After the first-generation Sanger technology, the second-generation technologies have found uptake (of which the dominant examples are the Genome Analyzer from Illumina, e.g. MiSeq or HiSeq (2); Roche 454 (33); and SOLiD from Applied Biosystems (44)) and even the third generation technologies have appeared (for example MinIon from Oxford Nanopore Technologies and PacBio RS from Pacific Biosciences). The Sanger method was used to sequence the first human genome for 15 years and the result was published at the beginning of the 21 st century, while the HiSeq X Ten System introduced in 2014 can sequence approximately 45 human genomes in 24 hours. It is worth adding that in addition to the time of sequencing being much shorter, its cost is now nearly 3,000,000 times lower (18).

HTS has also been introduced into vaccine research to swift and conspicuous effect. This technology provides a means to broaden knowledge of the complexity of the genomes of vaccine pathogens and their biological characteristics and interaction with the host organism, as well as immunogenetics in the broad sense. Besides the scientific benefits, HTS has also made it possible to design vaccines against certain pathogens for the first time (31). Systems of such a large bandwidth are the future of personalised creation of vaccines and understanding of the genotype - phenotype interaction (11).

\section{Modern vaccinology}

A vaccine is an immunotherapeutic preparation of biological origin containing antigens that stimulate the immune system of humans or animals to create immunity after their administration, in other words acquired immunity. The main task of immunotherapy is to protect public health. Vaccines are used for imparting controlled immunity comparable to natural immunity acquired after infection with wild-type organisms. The ability to stimulate the immune system is referred to as immunogenicity (24). There are many different vaccines and also many different methods for classifying them. Primarily they are divided into two groups. The first groups is live attenuated vaccines that contain a pathogen devoid of pathogenic properties. They cause a natural but non-pathogenic infection and confer lifelong immunity via lymphocyte memory cells. The second includes vaccines as a wide range of inactivated preparations which usually require adjuvants to enhance the induced immune response, e.g. inactivated toxins (diphtheria, tetanus), carbohydrate cocktails (Pneumococcus), subunit preparations (hepatitis B), and conjugate vaccines (Meningococcus, Haemophilus influenza type B) (6).

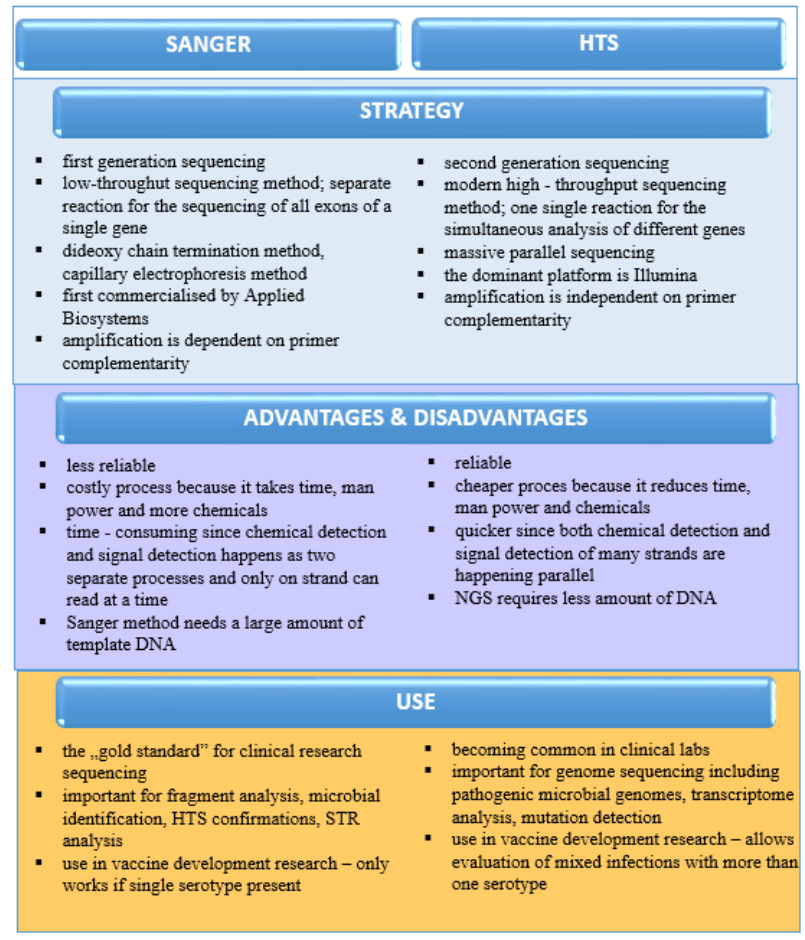

Fig. 2. Comparison of the Sanger method with the HTS technique $(17,36)$ 
A new branch of medicine dealing with protective vaccinations - vaccinology is a scientific discipline that deals with the vaccine in its concept. It extends not only over scientific research into the development of new vaccines, but also over their subsequent use (38), and hence encompasses post-vaccination immunology, administration of the vaccine, legal regulations, and vaccination methods, programmes and monitoring. Also in the realm of vaccinology is assessment of a vaccine's effectiveness as well as its impact on the environment (13). Immunisations have indisputably reduced the cost of treating clinical disease, but also the mortality from infectious diseases. The development of vaccinology has given the ability to control many deadly diseases, such as smallpox, diphtheria, polio, tuberculosis, measles and whooping cough. The flagship example is the eradication of smallpox (6). At the end of the eighteenth century, Edward Jenner proved his hypothesis correct that the pus in milkmaids'cowpox blisters could protect against smallpox. Jenner's finding was impactful by launching a global vaccination campaign in 1979, the total elimination of smallpox was achieved (30). It is one of many examples showing that vaccines have undoubtedly contributed to improving public health in the world.

Despite this, there are still many diseases that do not have an effective vaccine. The design of 21 st century vaccines is complicated because vaccinologists are currently dealing with rapidly evolving pathogens, and the help of HTS molecular biology tools is vital for this reason.

\section{HTS as a vaccine control tool}

The vast majority of vaccines contain strains originating from the field, which lose their initial virulence as a result of various physical or chemical treatments (i.e. multiple passage or temperature treatment). Phenotypic changes observed as nonvirulence are reflected in the genotype of a given pathogen. However, occasionally, vaccination-related side effects are observed and sometimes they are connected with the genomes of the vaccine strain. Examples of these side effects are those from vaccines against poliomyelitis caused by poliovirus (PV). The attenuation of vaccine strains involves the alteration of various nucleotides in the genome of PV, among other locations in the coding part of the VP1 or VP3 proteins. It was revealed that vaccine-associated paralytic poliomyelitis noted in recipients of the vaccine could be caused by vaccine strain revertants. That is why it is important to control the strains at the level of their genomes. Recently, the French Official Medicines Control Laboratory (OMCL) of the Agence Nationale de Sécurité du Médicament et des Produits de Santé (ANSM) reported the possibility of using the next generation sequencing (NGS) method as a vaccine quality control test. ANSM implemented a highthroughput sequencing method instead of the mutant analysis by polymerase chain reaction and restriction enzyme cleavage method for monitoring genetic mutations as a quality control test for inactivated poliovirus $(\mathrm{PV})$ vaccines. This allows the determination of neurovirulent viral repertoires in a shorter time, reduces the cost of research and, above all, eliminates the need to use radioactive isotopes (1). Scientists have proven that in the Sabin 3 strain, a mutation at nucleotide 472 of VP1 ( $U \rightarrow C$ exchange) was directly related to neurovirulence. The vaccine batch is not useable if the percentage of revertants containing $\mathrm{C}$ at the position of 472 is greater than $0.9 \%$ (1). Therefore, oral polio vaccines with serotype 3 must be monitored during the manufacturing process. This is necessary for the consistency and safety of vaccines and HTS is the perfect tool for this purpose (41).

Montmayeur et al. (35) described the use of HTS as a tool for a worldwide strategy of PV eradication and limitation of its spread. Prior to these researchers' innovation Sanger sequencing of the viral VP1 capsid region had been used for this purpose. Standard techniques used to prepare the material for HTS were optimised, such as the treatment of viral RNA with DNase, random reverse transcription, Nextera XT library preparation and amplification. This facilitated the detection of different poliovirus strains, mainly vaccinederived ones. Moreover, getting full genomes from Flinders Technology Associates cards improved the global surveillance of polioviruses (35).

The control of the genetic stability of microorganisms in vaccines is another example of HTS application in vaccinology. Liu et al. (28) published the results of genetic stability analyses of live attenuated A/17/California/2009/38 (H1N1) and A/17/Perth/09/87 (H3N2) strains of influenza virus in 2015. Both virus strains were inoculated into embryonated chicken eggs and passaged a low number of times, then the complete genome of individual generations of the strains (the second, third, fifth and tenth passages) was sequenced and analysed. The genes encoding haemagglutnin and neuraminidase were compared to genes of the wild-type virus strains, which were used in the production of immunological medicinal products. The tenth passage of strains emerged as still sharing $99 \%$ homology with the original, and therefore it was considered that live attenuated influenza vaccine strains are characterised by high genetic stability (28).

\section{HTS application in reverse engineering of vaccines}

The main application of HTS in medical research is the analysis of the genomes of pathogenic microorganisms. Additionally, with HTS host-pathogen interaction can be studied and differences in the immune response of the host with respect to B and T cells can be analysed (31). All these HTS possibilities have found application in vaccine research. Recently, a new term in vaccinology has appeared - vaccinomics. This is a multidisciplinary field taking elements from immunology and genetics, with the creation of an individual vaccination therapy as 
its main goal. Vaccinomics allows the designer of vaccines to achieve faster results in the production of vaccines than traditional vaccinology can deliver. One of the parts of vaccinomics is reverse vaccinology, the reverse engineering of vaccines (20).

Reverse vaccinology is for the prediction of the most immunogenic epitope. A whole genome elucidated using HTS is then screened by very specialised and effective bioinformatic tools to identify such epitopes $(20,42)$. Reverse vaccinology has enabled the design of vaccines against diseases such as anthrax, malaria, and meningitis (20). The bacterium Meningococcus B which causes the last of these diseases was actually first investigated by reverse vaccinology. The studies decoded the bacterial genome and assessed the antigenicity of over 600 potential antigens. Among the 90 detected surface proteins, $30 \%$ transpired to be capable of inducing bactericidal antibody secretion (23).

Reverse vaccinology recently focused on the identification of vaccine antigens by characterisation of the interactions between antigens and neutralising monoclonal antibodies (mAbs). Guo et al. (15) demonstrated that the identification of functional peptide antigens is possible by the use of an HTS-enhanced mRNA display approach for $\mathrm{mAb}$ interrogation. These antigens target the immune response and are useful in vaccine reverse engineering for pathogens against which strong neutralising antibodies are available. Peptides identified through this approach were injected into mice. Consequently, the mice produced antibodies that were able to prevent hepatitis $C$ virus infection (15). Reverse vaccinology may soon become the prescribed countermeasure against antibiotic-resistant pathogens. To this end, Zeb et al. (48) created a project to develop vaccines against cholera in the form of new proteins. It is worthwhile not only financially but also and primarily as it strengthens public health protection in countries where cholera causes many cases of diarrhoeal disease (48). The future of immunological science is the generation of vaccines against cancers, global infectious diseases (e.g. malaria, AIDS, and TB), allergies, autoimmune diseases, and new emerging diseases. The breadth of vaccine generation envisioned also creates a need for the development of next-generation adjuvants that would make vaccines more effective. One such promising adjuvant is cytosine triphosphate deoxynucleotidephosphodiester-guanine triphosphate deoxynucleotide. This compound added to the hepatitis B (HBV) vaccine increased the duration, size and kinetics of the seroprotective response $(10,23)$. Reverse vaccinology therefore also provides a tool for developing new adjuvants (39).

\section{Bioinformatic tools}

Thanks to the HTS technique, it is possible to determine the nucleotide sequence of a given test material from a specific organism. Then the obtained DNA sequences of different organisms are compared to discover the mechanisms of their evolution (14). To exploit this possibility most fully it is essential to make the discovered nucleotide sequences available via electronic databases (14). There are three basic databases that collect and share all discovered nucleotide sequences: one at the European Molecular Biology Laboratory (EMBL), GenBank, and the DNA Databank of Japan (DDBJ). The oldest is the EMBL database founded by the European Bioinformatics Institute (EBI) in Cambridge, UK in $1982(14,25)$. GenBank is maintained by the National Center for Biotechnology Information (NCBI) at the US National Institute of Health (NIH) in Bethesda, USA $(3,14)$. The third database, the DDBJ, was created in Japan in 1986 and is managed by the National Institute of Genetics (NIG) $(14,46)$. These centres operate independently of each other but permanently exchange all information by the International Sequence Database Collaboration (INSDC). Bioinformatics resources found there contain both pathogen and its immunological activity data, as well as genomic and transcriptomic information on various pathogens (42).

The increasing availability of sequencing results requires careful analysis using sophisticated IT tools, which allow the information contained in the genotype to be translated into what is observable at the phenotype level and then be used in vaccinology. In this aspect immunoinformatics is very useful. Urrutia-Baca et al. (47) have created a project for a multiepitopic oral vaccine against Helicobacter pylori - a bacterium recognised by the World Health Organization as a carcinogen of the first group, which has been observed to increase its antibiotic resistance during therapy. Through the application of the immunoinformatic approach, an antigenic, non-allergic soluble candidate vaccine against this carcinogenic bacterium was created (47).

\section{HTS in veterinary vaccines}

HTS is also increasingly used in veterinary vaccinology, both in the development and control of animal vaccines and in recognising the mechanism of virus strain attenuation. This method of learning how attenuation takes place was applied in the development of the vaccine against Marek's disease. The virus contained in this vaccine, gallid herpesvirus 2 (GaHV-2), was sequenced and it was revealed that serial passage causes the formation of mixed virus populations, which differ in the number and size of genetic changes after attenuation (45). Another example of the use of HTS in animal vaccinology is the search for genetic markers of vaccine strains. Knowledge of such markers would make it possible to quickly distinguish between vaccine and field strains. Such an attempt was made with the vaccine against infectious laryngotracheitis (ILT) of chickens (7). Moreover, a subsequent study on infectious laryngotracheitis virus (ILTV) showed the risk of using different attenuated vaccines in the same population of birds. It revealed that recombinations between vaccine strains led to the creation 
of virulent recombinant viruses responsible for the disease of Australian poultry flocks (26).

HTS is also used in virulence recovery studies on veterinary vaccines. It may happen that a given disease is effectively controlled by vaccines but despite this, regains of virulence by the disease's viral agent in these products are reported. This was the case with the vaccine against avian metapneumovirus (aMPV), which infects the respiratory tracts of domestic poultry. From the sequencing studies, a single nucleotide mutation in the vaccine was found that was consistent with the consensus sequence of the virulent adherent virus. Franzo et al. (12) state that such potentially virulent subpopulations of the vaccine strain may be involved in the return to virulence (12). However, the origin of these subpopulations, whether they arose as a result of virus evolution or were present from the very beginning among the vaccine virus genotypes but in a minority, is unknown. It is highly probable that these two mechanisms are not mutually exclusive. The final answer to these questions will only be found after further deep sequencing research (12).

Another problem in veterinary vaccinology is the distinction between the vaccine and the field strain. The strains included in veterinary vaccines, similarly to human ones, come from field strains that lose their original virulence due to various treatments. The loss of this virulence has consequences at the molecular level but very often they are unknown. However, it should be remembered that strains similar to the vaccine strain still circulate in the field. When a vaccine-like strain is detected in individuals with clinical symptoms of the disease, it raises the question of whether it is actually a vaccine strain or a vaccine-like wild-type one. This duality of possibility was raised by scientists from an Anglo-Italian research group in their publication on infectious bronchitis virus (IBV) vaccines. They appealed to producers to introduce a vaccine and a method (test) to distinguish it from wild-type strains at the same time (27). It seems that the HTS technique could be very useful in finding a suitably distinctive molecular marker.

\section{Needs for HTS reference materials}

A significant improvement in the quality of work with the HTS platform would be achieved through the introduction of validated reference standards. Interpretation of the HTS data depends on many factors, such as the complexity of the genome or technical errors resulting from both sequencing and sample preparation. Reference standards would help alleviate these errors by providing accurate data analysis (16). Deep sequencing makes it possible to identify foreign genetic material in a sample, even if we have no information on the probable contamination of that sample. HTS techniques have already been used to detect accidental factors in vaccines as well as cell lines or sera, so it seems that the creation and distribution of HTS reference standards is an extremely important issue for vaccine manufacturers and control laboratories (34). Currently, there are a considerable number of viral metagenomics methods and many options for creating sequencing libraries, but also many scientific and commercial bioinformatic platforms. These databases are constantly evolving. Therefore, it is important to have reliable reference materials to confirm that these different methods give comparable test results. Mee et al. (34) described the results of deep sequencing of vaccines and biologicals conducted by 16 different laboratories. A common reference material containing 25 known viruses was created for this study. These laboratories used various methods for sample preparation and bioinformatic analysis. Only six laboratories detected all 25 viruses, while a further ten laboratories detected 19 of the 25 viruses. This emphasises the need for common reference materials to be used by different laboratories (34). In turn, Khan et al. (22) carried out a virus research project using the HTS platform in cooperation with three laboratories. This study aimed to assess the effectiveness of using HTS in detecting unknown factors. Various platforms for the sequencing of the five model viruses: feline leukaemia virus (FeLV), human respiratory syncytial virus (RSV), Epstein-Barr virus (EBV), human reovirus (REO) and porcine circovirus (PCV) were used. The results were satisfactory because comparable HTS detection of different virus types was obtained. This project aimed to strengthen the argument for the future development of reference viral materials for the validation and standardisation of various HTS platforms (22).

\section{Potential use of HTS in the construction of coronaviruses vaccines}

At the end of 2019, a global pandemic broke out caused by a coronavirus which emerged first in Wuhan, Hubei Province, China. The World Health Organization (WHO) announced the standard format for referring to it, coronavirus disease-2019 (COVID-19), and the International Committee on the Taxonomy of Viruses (ICTV) named this novel coronavirus severe acute respiratory syndrome coronavirus 2 (SARS-CoV-2) (19). Coronaviruses (CoVs) are a group of many different viruses that have the potential to cause an epidemic because of their ability to cross the species barrier and spread rapidly in a new host species. There are several vaccines containing coronaviruses to immunise animals (especially against IBV caused by gammacoronaviruses), but until recently no vaccines existed to immunise humans, despite the severe public health threat of diseases caused by the CoVs (43). Therefore, the scientific world has recently been looking for safe and effective immunoproducts for SARS-CoV-2 which could be quickly put into production at scale $(8,49,21)$. HTS platforms became a helpful tool in the scientific race against time. Recent HTS analysis showed that SARSCoV-2 shares overall genomic similarity with SARS-CoV (79\%) and some even with Middle East respiratory syndrome coronavirus (MERS-CoV) (50\%). Precise sequence comparison of each gene region may give 
a better answer as to how SARS-CoV-2 interferes with the host immune response. It seems that SARS-CoV-2 utilises strategies to modulate the host innate immune response similar to those of MERS-CoV (37). HTS was also used to identify SARS-CoV-2 tropism and revealed that the spike protein receptor-binding domain of the virus uses angiotensin-converting enzyme 2 as a cell receptor (37). The COVID-19 situation made the necessity to protect human life the most exigent obligation and many scientific centres began to work on vaccines aimed at minimising the clinical manifestations of the disease. Various ideas have been used in the development of these vaccines: inactivated virus, nucleic acid, adenovirusbased vectors, and recombinant subunits. Studies carried out at the Gamaleya Research Institute of Epidemiology and Microbiology (Russia) developed a vaccine (Sputnik V) which consists of two components, recombinant adenovirus type 5 and recombinant adenovirus type 26 vectors, and both of them contain the gene for SARSCoV-2 spike glycoprotein (29). A similar but single adenovirus-based vaccine was developed by the OxfordAstraZeneca and Johnson \& Johnson teams. After more than twenty years of research on the development of vaccines based on messengerRNA (mRNA) technology, they are commercialised by two companies, Pfizer/ BioNTech and Moderna. It should be added that the first vaccine against COVID-19 approved for use in the European Union was the Comirnaty vaccine from Pfizer/BioNTech. Soon after, sanctioned by the positive evaluation the European Medicines Agency, the European Commission approved the mRNA-1273 vaccine from Moderna. A similar idea of mRNA will be the basis of a vaccine being developed by the German CureVac company. A protein-based coronavirus vaccine is also under development, as well as several which contain inactivated virus. All the vaccines in use are highly effective, ranging from $70-95 \%$ depending on the dose used. However, there is concern over how effective these vaccines will be against the emerging new SARSCoV-2 variants. Their detection is only possible exploiting HTS technology.

Conflict of Interests Statement: The authors declare that there is no conflict of interests regarding the publication of this article.

Financial Disclosure Statement: This study was funded by the statutory activity of the National Veterinary Research Institute in Puławy.

Animal Rights Statement: Not applicable.

\section{References}

1. André M., Bridon J.M., Boussard E., Maisonneuve S., Lempereur L.: Next Generation Sequencing (NGS) for monitoring ultra-low level of genetic mutation as a quality control test of live poliovirus vaccine. Agence Nationale de Sécurité du Médicament et des Produits de Santé, Lyon, 2016, doi: 10.13140/RG.2.2.30124. 87687, https://www.researchgate.net/publication/311257310.
2. Bennett S.T., Barnes C., Cox A., Davies L., Brown C.: Toward the 1,000 dollars human genome. Pharmacogenomics 2005, 6, 373-382, doi: 10.1517/14622416.6.4.373.

3. Benson D., Karsch-Mizrachi I., Lipman D., Ostell J., Wheeler D., Genbank. Nucleic Acids Res, 35 (supplement 1), 2007, D21-D25, doi: 10.1093/nar/gk1986.

4. Brown T.A.: Genomy. Wydawnictwo Naukowe PWN, Warsaw 2001, 36, pp. 60-70.

5. Cafardi V., Telford J.L., Serruto D.: Bacterial Genomes and Vaccine Design. In: Immunomic Discovery of Adjuvants and Candidate Subunit Vaccines, edited by D.R. Flower, Y. Perrie, Springer, London, 2013, pp. 13-37, doi: 10.1007/978-1-4614-5070-2.

6. Centlivre M., Combadière B.: New challenges in modern vaccinology. BMC Immunol 2015, 16, 18, doi: 10.1186/s12865-015-0075-2.

7. Chandra Y.G., Lee J., Kong B. W.: Genome sequence comparison of two United States live attenuated vaccines of infectious laryngotracheitis virus (ILTV). Virus Genes 2012, 44, 470-474, doi: 10.1007/s11262-012-0728-7.

8. Chen W.H., Strych U., Hotez P.J., Bottazzi M.E.: The SARSCoV-2 Vaccine Pipeline: an Overview. Curr Trop Med Rep 2020, 7, 61-64, doi:10.1007/s40475-020-00201-6.

9. Chwiałkowska K.: Pirosekwencjonowanie - sekwencjonowanie z wykorzystaniem kwantów światła (Pyrosequencing sequencing by quanta of light) 2009. http://www.biotechnolog.pl/ pirosekwencjonowanie-sekwencjonowanie-z-wykorzystaniemkwantow-swiatla.

10. Cooper C.L., Angel J.B., Seguin I., Davis H.L., Cameron D.W.: CPG 7909 adjuvant plus hepatitis B virus vaccination in HIVinfected adults achieves long-term seroprotection for up to 5 years. Clin Infect Dis 2008, 46, 1310-1314, doi: 10.1086/533467.

11. Dhiman N., Smith D.I., Poland G.A.: Next-generation sequencing: a transformative tool for vaccinology. Expert Rev Vaccines 2009, 8, 963-967, doi: 10.1586/erv.09.67.

12. Franzo G., Naylor C.J., Drigo M., Croville G., Ducatez M.F., Catelli E., Laconi A., Cecchinato M.: Subpopulations in aMPV vaccines are unlikely to be the only cause of reversion to virulence. Vaccine 2015, 33, 2438-2441, doi: 10.1016/j.vaccine.2015.03.092.

13. Gardin Y., Palya V., Paniago M., Cazaban C., Alva B., Lozano F., El Attrache J., Ceva Animal Health: Gumboro Disease Special. The rational use of vaccines and vaccinations for real control of Gumboro disease. World Poultry 2014, April Supplement.

14. Gruca A.: Bioinformatyczne bazy danych (Bioinformatics databases - in Polish). Wydawnictwo PJWSTK, Warsaw, 2010.

15. Guo N., Duan H., Kachko A., Krause B.W., Major M.E., Krause P.R.: Reverse Engineering of Vaccine Antigens Using High Throughput Sequencing-enhanced mRNA Display. EBioMedicine 2, 2015, 859-867, doi: 10.1016/j.ebiom.2015.06.021.

16. Hardwick S.A., Deveson I.W., Mercer T.R.: Reference standards for next-generation sequencing. Nat Rev Genet 2017, 18, 473-484, doi: 10.1038/nrg.2017.44.

17. Hogrefe W., Hurban P.: A Next Generation Sequencing (NGS) Approach to Influenza Vaccine Development. Nature Res Custom Media 2020, https://www.nature.com/articles/d42473-020-00389-1.

18. Illumina: Introduction to NGS http://www.illumina.com/ technology/next-generation-sequencing.html.

19. Jin Y., Yang H., Ji W., Wu W., Chen S., Zhang W., Duan G.: Virology, Epidemiology, Pathogenesis, and Control of COVID19. Viruses 2020, 12, 372, doi: 10.3390/v12040372.

20. Kanampalliwar A.M., Soni R., Girdhar A., Tiwari A.: Reverse Vaccinology: Basics and Applications. J Vaccines Vaccin 2013, 4, 1-5, doi: 10.4172/2157-7560.1000194.

21. Kaur S.P., Gupta V.: COVID-19 Vaccine: A comprehensive status report. Virus Res 2020, 288, 198114, doi: 10.1016/j.virusres.2020. 198114.

22. Khan A.S., Ng S.H.S., Vandeputte O., Aljanahi A., Deyati A., Cassart J.-P., Charlebois R.L., Taliaferro L.P.: A Multicenter Study To Evaluate the Performance of High-Throughput Sequencing for Virus Detection. mSphere 2017, 5, 1-19, doi: 10.1128/mSphere.00307-17.

23. Koff W.C., Burton D.R., Johnson P.R., Walker B.D., King C.R., Nabel G.J., Ahmed R., Bhan M.K., Plotkin S.A: Accelerating Next Generation Vaccine Development for Global Disease 
Prevention. Science. 2013, 31, 340, 1232910, doi: 10.1126/science. 1232910.

24. Kuchar E.: Klasyfikacja i skład szczepionek (Classification and composition of vaccines - in Polish). https://www.mp.pl/pacjent/ choroby-zakazne/szczepienia/158371,klasyfikacja-i-sklad-szczepionek.

25. Kulikova T., Akhtar R., Aldebert P., Althorpe N., Andersson M., Baldwin A., Bates K., Bhattacharyya S., Bower L., Browne P., Castro M., Cochrane G., Duggan K., Eberhardt R., Faruque N., Hoad G., Kanz C., Lee C., Leinonen R., Lin Q., Lombard V., Lopez R., Lorenc D., McWilliam H., Mukherjee G., Nardone F., Garcia Pastor M.P., Plaister S., Sobhany S., Stoehr P., Vaughan R., Wu D., Zhu W., Apweiler R.: EMBL nucleotide sequence database in 2006. Nucleic Acids Res 2007, 35, D16-D20, doi: 10.1093/nar/gk1913.

26. Lee S.W., Markham P.F., Coppo M.J., Legione A.R., Markham J.F., Noormohammadi A.H., Browning G.F., Ficorilli N., Hartley C.A., Devlin J.M.: Attenuated vaccines can recombine to form virulent field viruses. Science 2012, 337, 188, doi: 10.1126/science.1217134.

27. Listorti V., Laconi A., Catelli E., Cecchinato M., Lupini C., Naylor C.J.: Identification of IBV QX vaccine markers : Should vaccine acceptance by authorities require similar identifications for all live IBV vaccines? Vaccine 2017, 35, 5531-5534, doi: 10.1016/j.vaccine.2017.06.021

28. Liu L., Zang Y., Jiang H., Xu F., Zhu C., Ge P., Liu X., Zhang Y., Jiang C.: Analysis of the genetic stability of the master virus seeds for live attenuated influenza vaccine production. Chin J Microbiol Immunol 2015, 35, 281-285, doi: 10.3760/cma.j.issn.02545101.2015.04.009, https://www.researchgate.net/publication/ 282376333_Analysis_of_the_genetic_stability_of_the_master_vi rus_seeds_for_live_attenuated_influenza_vaccine_production.

29. Logunov D.Y., Dolzhikova I.V., Zubkova O.V., Tukhvatulin A.I., Shcheblyakov D.V., Dzharullaeva A.S., Grousova D.M., Erokhova A.S., Kovyrshina A.V., Botikov A.G., Izhaeva F.M., Popova O., Ozharovskaya T.A., Esmagambetov I.B., Favorskaya I.A., Zrelkin D.I., Voronina D.V., Shcherbinin D.N., Semikhin A.S., Simakova Y.V., Tokarskaya E.A., Lubenets N.L., Egorova D.A., Shmarov M.M., Nikitenko N.A., Morozova L.F., Smolyarchuk E.A., Kryukov E.V., Babira V.F., Borisevich S.V., Naroditsky B.S., Gintsburg A.L.: Safety and immunogenicity of an rAd26 and rAd5 vector-based heterologous prime-boost COVID-19 vaccine in two formulations: two open, nonrandomised phase 1/2 studies from Russia. Lancet 2020, 26, 396, 887-897, doi: 10.1016/S0140-6736(20)31866-3.

30. Loomis R.J., Johnson P.R.: Emerging Vaccine Technologies. Vaccines 2015, 3, 429-447, doi: 10.3390/vaccines3020429.

31. Luciani F.: High-throughput sequencing and vaccine design. Rev Sci Tech 2016, 35, 53-65, doi: 10.20506/rst.35.1.2417.

32. Maniecka M.: Metody sekwencjonowania DNA (DNA sequencing methods - in Polish). http://laboratoria.net/artykul/12972.html, https://docplayer.pl/59379591-Tytul-metody-sekwencjonowania-dna -autor-magdalena-maniecka-data-publikacji.html.

33. Margulies M., Egholm M., Altman W.E., Attiya S., Bader J.S., Bemben L.A., Berka J., Braverman M.S., Chen Y.-J., Chen Z., Dewell S.B., Du L., Fierro J.M., Gomes X.V., Godwin B.C., He W., Helgesen S., Ho C.H., Irzyk G.P., Jando S.C., Alenquer M.L., Jarvie T.P., Jirage K.B., Kim J.-B., Knight J.R., Lanza J.R., Leamon J.H., Lefkowitz S.M., Lei M., Li J., Lohman K.L., Lu H., Makhijani V.B., McDade K.E., McKenna M.P., Myers E.W., Nickerson E., Nobile J.R., Plant R., Puc B.P., Ronan M.T., Roth G.T., Sarkis G.J., Simons J.F., Simpson J.W., Srinivasan M., Tartaro K.R., Tomasz A., Vogt K.A., Volkmer G.A., Wang S.H., Wang Y., Weiner M.P., Yu P., Begley R.F., Rothberg J.M.: Genome sequencing in microfabricated high-density picolitre reactors. Nature 2005, 437, 376-380, doi: 10.1038/nature03959.

34. Mee E.T., Preston M.D., Minor P.D., Schepelmann S.: Development of a candidate reference material for adventitious virus detection in vaccine and biologicals manufacturing by deep sequencing. Vaccine 2016, 17, 2035-2043, doi: 10.1016/j.vaccine.2015.12.020.

35. Montmayeur A.M., Ng T.F., Schmidt A., Zhao K., Magaña L., Iber J., Castro C.J., Chen Q., Henderson E., Ramos E., Shaw J., Tatusov R.L., Dybdahl-Sissoko N., Endegue-Zanga M.C., Adeniji J.A., Oberste M.S., Burns C.C.: High-Throughput NextGeneration Sequencing of Polioviruses. J Clin Microbiol 2017, 55, 2, 606-615, doi: 10.1128/JCM.02121-16.

36. Nentwich M.M., Rudolph G.: Hereditary retinal eye diseases in childhood and youth affecting the central retina. Oman J Ophthalmol 2013, 6, 18-25, doi: 10.4103/0974-620X.122290.

37. Prompetchara E., Ketloy C., Palaga T.: Immune responses in COVID-19 and potential vaccines: Lessons learned from SARS and MERS epidemic. Asian Pac J Allergy Immunol 2020, 38, 1-9, doi: 10.12932/AP-200220-0772.

38. Raeven R.H.M., van Riet E., Meiring H.D., Metz B., Kersten G.F.A.: Systems vaccinology and big data in the vaccine development chain. Immunology 2019, 156, 33-46, doi: 10.1111/imm.13012.

39. Rappuoli R.: Reverse vaccinology. Curr Opin Microbiol 2000, 3, 445-450, doi: 10.1016/S1369-5274(00)00119-3.

40. Sanger F., Nicklen S., Coulson A.R.: DNA sequencing with chainterminating inhibitors. Proc Natl Acad Sci USA 1977, 74, 5463-5467, doi: 10.1073/pnas.74.12.5463.

41. Sarcey E., Serres A., Tindy F., Chareyre A., Ng S., Nicolas M., Vetter M., Bonnevay T., Abachin E., Mallet L.: Quantifying lowfrequency revertants in oral poliovirus vaccine using next generation sequencing. J Virol Methods 2017, 246, 75-80, doi: 10.1016/j.jviromet.2017.04.016.

42. Sette A., Rappuoli R.: Reverse Vaccinology: Developing Vaccines in the Era of Genomics. Immunity. 2010, 33, 530-541, doi: 10.1016/j.immuni.2010.09.017.

43. Shen L., Niu J., Wang C., Huang B., Wang W., Zhu N., Deng Y., Wang H., Ye F., Cen S., Tan W.: High-Throughput Screening and Identification of Potent Broad-Spectrum Inhibitors of Coronaviruses. J Virol 2019, 93, e00023-19, doi: 10.1128/JVI.00023.

44. Shendure J., Porreca G.J., Reppas N.B., Lin X., McCutcheon J.P., Rosenbaum A.M., Wang M.D., Zhang K., Mitra R.D., Church G.M.: Accurate multiplex polony sequencing of an evolved bacterial genome. Science 2005, 309, 1728-1732, doi: 10.1126/science.1117389.

45. Spatz S.J.: Accumulation of attenuating mutations in varying proportions within a high passage very virulent plus strain of Gallid herpesvirus type 2. Virus Res 2010, 149, 135-142, doi: 10.1016/j.virusres.2010.01.007.

46. Sugawara H., Ogasawara O., Okubo K., Gojobori T., Tateno Y.: Nucleic Acids Res. 2008, 36 (Database issue), D22-D24, doi: 10.1093/nar/gkm889.

47. Urrutia-Baca V.H., Gomez-Flores R., De La Garza-Ramos M.A., Tamez-Guerra P., Lucio-Sauceda D.G., Rodríguez-Padilla M.C.: Immunoinformatics Approach to Design a Novel Epitope-Based Oral Vaccine Against Helicobacter pylori. J Comput Biol 2019, 26, 1177-1190, doi: 10.1089/cmb.2019.0062.

48. Zeb S., Ali A., Gulfam S.M., Bokhari H.: Preliminary Work Towards Finding Proteins as Potential Vaccine Candidates for Vibrio cholerae Pakistani Isolates through Reverse Vaccinology. Medicina 2019, 55, 195, doi: 10.3390/medicina55050195.

49. Zhu F.-C., Li Y.-H., Guan X.-H., Hou L.-H., Wang W.-J., Li J.-X., Wu S.-P., Wang B.-S., Wang Z., Wang L., Jia S.-Y., Jiang H.-D., Wang L., Jiang T., Hu Y., Gou J.-B., Xu S.-B., Xu J.-J., Wang X.-W., Wang W., Chen W.: Safety, tolerability, and immunogenicity of a recombinant adenovirus type- 5 vectored COVID-19 vaccine: a dose-escalation, open-label, nonrandomised, first-in-human trial. Lancet 2020, 395, 1845-1854, doi: 10.1016/S0140-6736(20)31208-3. 